\section{ECONOMICS}

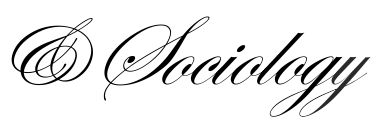

Balcerak, A., \& Woźniak, J. (2021). Reactions to some ICT-based personnel selection tools. Economics and Sociology, 14(1), 214-231. doi:10.14254/2071789X.2021/14-1/14

\title{
REACTIONS TO SOME ICT-BASED PERSONNEL SELECTION TOOLS
}

\author{
Alicja Balcerak \\ Wrocław Technical University, \\ Wroctaw, Poland \\ ORCID: 0000-0002-4507-0497 \\ E-mail:alicja.bacerak@,pwr.edu.pl

\begin{abstract}
Jacek Woźniak
University of Economics and

Human Sciences, Warsaw, Poland, ORCID 0000-0003-4610-2822

E-mail:j.wozniak@vizja.pl
\end{abstract}

\author{
Received: April, 2020 \\ 1st Revision: December, 2020 \\ Accepted: March, 2021
}

DOI: $10.14254 / 2071-$

789X.2021/14-1/14
ABSTRACT. If human resource management (HRM) tools based on information technologies (ICT) are to support organizational effectiveness, it is imperative that these tools are accepted by employees. Knowledge concerning how ICT-based selection tools are perceived by potential employees is limited, which was the impulse for this research. A standard methodology for studies into fairness assessment of recruitment tools was followed here. Descriptions were prepared for five new ICT-based selection tools (long-distance synchronic interview; game results and analysis of candidates' behaviour while playing a computer game; gathering information over the internet in the form of content-based analytics and structurebased analytics). Data from 833 Polish candidates collected using an e-questionnaire showed that fairness assessment for the five new selection tools is lower than for their traditional counterparts, i.e., interview, work samples, references and biodata questionnaire. It was also shown that the internet experience - measured by frequency of its use - and belonging to a younger generation do not significantly affect higher acceptance of ICT-based methods. The article indicates what kinds of activities may be undertaken to increase this acceptance.

Keywords: fairness assessment, ICT based selection tools, selection of employees, ICT in HR, Human Resource Management J210, J230, M51

\section{Introduction}

Poland, which has successfully transformed itself from a centrally controlled economy to a market economy, is now a good example of an emerging economy. Recently, after many years of high unemployment and an easy - from an employer's perspective - labor market, Polish companies have started to face difficulties in attracting workers. This encourages interest in those selection tools which are not only predictive but also accepted by potential candidates. Hence the practical importance of the research on the candidates' perception of fairness in the selection tools.

Research on the perception of selection methods' fairness by potential employees has been carried out for more than 30 years, primarily based on the uniform theoretical and methodological approach worldwide (Nikolaou \& Oostrom, 2015; Ployhart, Schmitt \& Tippins 2017; Truxillo et al., 2018). However, most of such data has been collected from the markets of developed countries, usually the United States and Western European countries (Liu, 
Potočnik \& Anderson 2016), and the research consensus on the independence of this perception from the country in which the study is conducted (Anderson, Salgado \& Hülsheger 2010) is based primarily on the data from the countries that do not have a fresh experience transforming from socialism. The research conducted by D. Ipsas et al. is an exception (2010) which shows a discrepancy between the assessments of fairness of the selection tools made by Romanian respondents and the aforementioned consensus (Hausknechta et al., 2004; Anderson, Salgado $\&$ Hülsheger, 2010). The authors explained this with the specificity of the country after its transformation from the politicized decisions of socialism to the state of a meritocratic economy (Ipsas et al. 2010, p. 110).

Poland, which has undergone such transformation earlier than Romania, is an example of a society with unstable social norms clashing with advanced technologies. This includes extensive use of the latest technologies in HRM (Strohmeier \& Kabst, 2009) along with rapid changes at the labor market. In particular, in the last 30 years, Poland has transitioned from the employee market to the employer market, and back to the employee market, accompanied by large-scale migrations of employees from and into the market. This indicates the supra-local importance of research on the perception of selection tools in Poland, especially in relation to those tools that are based on the latest information technologies. At the same time, however, it makes it possible to check whether the anomalies found in the study (Ipsas et al., 2010) indicate rather the specificity of exiting the socialist economy or the specificity of respondents from the Eastern Europe.

The overarching aim of the current study is to assess the fairness of the selected selection tools and, more specifically, whether the selection tools which are based on information and communication technologies (hereinafter referred to as ICT) have a lower level of perceived fairness than their traditional counterparts. Based on the methodology introduced by Steiner and Gulliland (1996), five traditional selection tools and five corresponding new tools based on ICT were evaluated. Such an approach is a step towards filling the gap in scientific knowledge indicated in the study of McCarthy et al. (2017) who stressed the lack of research on the perception of fairness of the ICT-based selection tools, using data from the labor market, which is technologically advanced, although developing in economic terms and standards.

The study is structured as follows. First, the assumptions of the study are presented, explaining the specificity of the selection tools analyzed and the reasons for their selection. The test methodology and hypotheses are then explained. The next part presents the results of the study, and the following part - their discussion. The study ends with a summary and an indication of the directions for further research.

\section{Traditional and ICT-based methods}

The use of ICT-based tools in the selection processes has aroused interest among researchers for years. However, as it is stressed in literature reviews (McCarthy et al., 2017; Ployhart, Schmitt \& Tippins, 2017), there are few studies which directly address the problem of acceptance of ICT-based selection methods, although there have been results showing low or conditioned acceptance for some tools, for instance, social media content research (Madeira, 2012; Aguado et al., 2016; Suen, 2018) or Artificial Inteligence based selection tools (Mirowska, 2020).

Internet content testing is an example that clearly shows the specificity of using ICTs for selection testing. This name is used to describe various selection tools if they are classified from the perspective of assessing the validity of forecasting career success of persons on the basis of data obtained in this way. Hence, investigating the perception of selection tools which implement ICTs requires a clarification of the specific behavior and conduct of the recruiter in 
order to discuss the selection tool, that is, the behavior that can be attributed to the estimation of the potential predictive accuracy.

This understanding of "ICT-based selection tools" suggests looking at the recruiter's actions through the lens of solutions similar to traditional tools. Therefore, for the purposes of the study, the selection tools frequently used in Poland were treated as the starting point, namely, the selection interview, CV (résumé), reference searching and work samples (Woźniak, 2013), which were juxtaposed with specific solutions that can be used by organizations which have ICT tools at their disposal. In addition - due to the role that an analogous tool plays in ICT-based research, a biographical questionnaire has been included in traditional tools, although it is not widely used in practice in the Polish labor market (Woźniak, 2013). Both the lists of ICT-based and traditional selection tools to which the study refers are therefore not exhaustive and have been selected to compare chosen selection tools with well-researched predictive validity with appropriate ICT-based tools, the use of which is justified by analogous inferences.

Selection interview is a commonly used selection method in Poland and worldwide. ICT enables several solutions, which can be named a selection interview conducted with technological support (Blacksmith, Willford \& Behrend, 2016; Woods et al., 2020). These include asynchronous interviews, based on providing the candidate with a list of questions via chat, but also synchronous interviews via communicators such as Skype, in which both parties not only hear each other, but also see each other and their reactions in real time. The experience of communicating with Skype is widespread among Poles - due to emigration being at a level higher than $10 \%$, Skype helps families maintain daily contact - and thus, it can be considered that a synchronous interview should be unproblematic for potential job candidates. The knowledge of the candidates' expectations towards the selection process also suggests a preference for interaction with the recruiter (Uggerslev, Fassina, \& Kraichy, 2012).

The thesis stating that the difference in traditional and online (Skype) communication should be small is directly or indirectly related to two theories - the media richness theory (McCarthy et al., 2017) and the technology acceptance model (TAM) (Davis, 1989), with further enlargements (Venkatesh, Thong, \& Xu, 2012). The media richness theory indicates that the lower the richness of a given medium, the less accepted communication using it is (McCarthy et al., 2017), which suggests a lower level of acceptance for interviews via Skype than for traditional methods. The TAM assumes that perceived ease of use and perceived usefulness, together with social norms operating in the environment (Venkatesh, Thong, \& Xu, 2012), are contributing to the intention to use new technological solutions. Therefore, it can be assumed that although ease of use and perceived usability are at least as high as for traditional means - and perhaps even higher in the case of Skype than for traditional interviews, as travel costs and other inconveniences related to the specific location of the recruiter disappear - the relative rarity of Skype interviews in recruitment suggests lower (rather than higher) acceptability of these interviews. However, it should be noted that conclusions based on TAM are made by analogy, since the recruited person does not decide to use the new technology, but is subject to it. To sum up, one should expect a lower level of acceptance for Skype interviews than for traditional interviews (based on the media richness theory and the rarity of social norms regarding such use), despite the benefits that the recruiter derives from online interviews.

H.1. Skype interviews will be rated lower than traditional interviews.

The second frequently used selection tool is references checking. In a traditional selection, it is used as a tool to check and supplement some information given by the candidate by interviewing people who have worked with the candidate in the past, usually their former 
superiors. Nowadays, substantial information about the candidate, coming from them and others, is available on the Internet and can be used as a reference check. Previous studies have shown that candidates negatively evaluate the search for information about them in social networks (Marler, 2012; Aguado et al., 2016), which suggests that this way of obtaining information for selection purposes will be rated low. The fact that this assessment will be perceived less favorable - as we expect - than personal references checking can be inferred from the fact that the quality of the information collected in this way, that is, coming from people with vastly varied levels of knowledge about the candidate and who may sometimes judge them harshly, may be lower if companies do not use careful assessment of the quality of the information collected. However, one needs to bear in mind that scientifically justified and well-procedured ways of such analysis may receive a more favorable assessment. The scientific literature distinguishes two separate ways of studying social networks, using - for analyses based on statistical methods - separate types of data contained in social networks, namely data containing the comments of users (content-based analytics) and data containing relations between users (structure-based analytics) (Gandomi \& Haider, 2015; McCarthy et al., 2017).

H2. Reference checking by collecting information on the Internet, whether in the form of content-based analytics or structure-based analytics, will be rated lower than traditional reference checking.

The third group of tools, which are often used in selection, are those based on the observation of the candidate's behavior during the performance of certain tasks. A classic example of such a tool is a work sample, namely the implementation of a selected task during the recruitment process, which serves as a sample - although specific ones as to its characteristics - of tasks that are part of everyday work. In an extensive form and focused mainly on the assessment of interpersonal and social competences, simulated work samples are also used, for instance, as part of an Assessment Center. The use of computer games makes it possible to build cheaper tools than Assessment Centers to evaluate candidates on the basis of simulated performance of tasks analogous to those entailed in the job. Again, two separate methodologies are used to assess a candidate playing a video game. One is based on the candidate's results in certain tasks in a game, and the other - on the basis of observations of his actions during the task copletion (Woźniak, 2017; Woźniak 2020; Armstrong, Landers \& Collmus, 2016).

The selection based on traditional work samples is well received by candidates. It can be expected, however, that the assessment by means of a simulated work sample using a video game will be assessed worse than the classic work samples, because comparing a player's behavior in a simulation to everyday behavior may be questionable (Woźniak, 2017; Woźniak 2020).

H.3. Verification of competence by means of collecting information from playing videogames, whether in the form of game outcomes' analysis or observation of the player's behavior, will be assessed worse than by means of traditional work samples.

However, the growing popularity of video games and their importance in leisure activities of Poles (GUS, 2017) suggest that knowledge about the possibility of predicting competences on the basis of playing video games, provided that these predictions are based on careful scientific research, is already common. Therefore, it can be assumed that the evaluation of tests with work samples and simulated work samples will be similar, which makes hypothesis 3 not obvious. 
The rationale behind the fact that from the study of behavior in areas separate from everyday tasks, such as behavior in social media or video games, it is possible to predict a candidate's future behavior at work arises by referring not so much to competences as to biographical events from the lives of employees, which were verified to ensure that the proposed solutions correctly predict success at work (concurrent validation - Scroggins et al., 2008, p. 187). This method of inference is characteristic of biodata inventory, a traditional selection tool which, if carefully prepared, is as accurate in prediction of work success as selection interviews (Breaugh, 2009).

Traditional biodata inventory collects information about the candidate's past experiences through extensive questionnaires. In Poland this tool is currently not used and may be confused by candidates with a $\mathrm{CV}$ which is considered necessary and has to be submitted with each application. It can therefore be expected that these tools will be similarly rated, although their atypical nature suggests that the ratings will be lower.

H4. Selection methods based on video games (analysis of the game outcome or the player's behavior) or Internet presence (content-based or structure-based) will be rated lower than traditional application questionnaire analysis.

To test the above hypotheses four traditional tools and five of their respective ICT-based counterparts have been selected for the study. In addition, in order to check whether the respondents make a proper distinction between a $\mathrm{CV}$ and an application questionnaire collecting biographical data, the perception of $\mathrm{CV}$ was also examined. The list of investigated tools is presented in Table 1 .

Table 1. Traditional selection methods and their ICT-based counterparts

\begin{tabular}{cc}
\hline Traditional & ICT-based \\
\hline Interviews & Long-distance interview \\
\hline Personal references & Internet - content-based analytics \\
& Internet - structure-based analytics \\
\hline Application questionnaire & Assessment based on activity in games \\
& Assessment based on game results \\
& Internet - content-based analytics \\
& Internet - structure-based analytics \\
\hline Work-sample & Assessment based on activity in games \\
& Assessment based on game results \\
\hline
\end{tabular}

\section{Source: own compilation}

The specific hypotheses $\mathrm{H} 1--\mathrm{H} 4$ can be integrated into the general hypothesis stating lower favorability ratings for ICT-based tools than for traditional ones. At the same time, on the basis of the argumentation previously presented, it can also be assumed that the Internet experience will be a factor influencing the level of acceptance of ICT-based tools (Sinar, Reynolds \& Paquet, 2003). Indeed, extended of Internet experience influence perceived ease of use of ICT-based tools, and thus indirectly contributes to acceptance. This can be explained by referencing to the basic version of TAM, which states that perceived ease of use fosters the intention of use the technology (Davis, 1989). This allows for the formulation of a second general hypothesis that the Internet experience, whether measured directly or by its indicator such as belonging to a younger generation (Deal, Altman \& Rogelberg, 2011; Twenge, 2010; Lyons \& Kuron, 2014; Woźniak, 2014), influence the ICT-based selection methods acceptation. The unobvious nature of this hypothesis results, on the one hand, from analogical reasoning, and, on the other hand, from the expectation that an extensive Internet experience is also conductive to a greater scale of negative experiences related to the violation of privacy, and 
thus - the reluctance to disclose information on the Internet (Bansal, Zahedi, \& Gefen, 2016), which should result in lower acceptance towards being the subject of online recruiting.

As a result, our research is testing two main hypotheses, while the above $\mathrm{H} 1-\mathrm{H} 4$ refer to the specific ICT-based tools

HA. ICT-based selection methods are rated lower than traditional ones.

HB. (a) Generational affiliation and (b) Internet experience affect ICT-based selection methods' acceptance.

As the survey will be based on a standard methodology (Steiner \& Gulliland, 1996), data concerning the evaluation of traditional selection methods will also be collected. The research procedure of this study has been used many times (Anderson, Salgado, \& Hülsheger, 2010; Bilgic \& Acarlar, 2010; Ispas et al., 2010; Anderson, Ahmed \& Costa, 2012; Liu, Potočnik \& Anderson, 2016), despite its arduousness for respondents (Bilgic \& Acarlar, 2010). The results of previous research suggest that the differences in favorability ratings between respondents from different countries are small and due to the scale of acceptance the selection tools can be divided into four groups: with rating above 3.5 points on the 5-point Likert scale in both meta-analyses (Hausknechta et al., 2004 and Anderson et al., 2010): interviews (3.7/3.96), work samples (3.61/3.84), and CV (3.57/3.55); rated lower but still positively: written aptitude tests (3.11/3.28), reference checking (3.29/3.11), biographical inventories (2.81/3.06), and personality tests (2.83/2.91); and least rated: integrity tests (2.47/2.64), checking the candidate's contacts within the organization (2.51/1.85), and graphology (1.69/1.66) (Truxillo et al., 2018, Table 1). When calculating the given data on a 7-point scale, it means a group of tools rated above 5 points; a group of about 4.2-4.5; a group of about 3.5 and a group of about 2.4 and not accepted graphology (rated around 1.7).

The only study conducted with this methodology on an Eastern European sample (Ispas et al., 2010) showed different results - all traditional tools, except for personal contacts (distinguished in this study from reference checking, which did not differ in rating from personality tests, rated about 5.3), graphology, and selection by ethnicity (discrimination of Roma) was rated above 5, while work samples were rated about 6.3 which significantly exceeded the rating of the selection interview, which was rated - similarly to CV or tests - at about 5.7-5.9. The interpretation of these unexpected results proposed by Ispas et al. (2010) referred to the consequences of the politicization of workers' selection in socialist Romania and was based on the conviction that a more formalized selection method is considered more fair than a selection which is characteristic of communism - based on party obedience and personal contacts. Considering such an explanation to be at least partially accurate, the results of the current study should be expected to be closer to the worldwide data-based consensus than to those of Romania just after the last Ceausescu collaborators were removed from government. This means that the study will additionally address the question whether the anomaly observed in the study (Ispas et al., 2010) can also be seen in the data collected in Poland.

\section{Methodology of the study}

\subsection{Method}

The research methodology is based on a classic study by Steiner and Gulliland (1996), who analyzed acceptance a tool by differentiating between distributive and procedural justice. These are measured using a questionnaire with 2 questions indicative of distributional justice, and 7 questions indicative of procedural justice, with a 7-point Likert scale for each question. 
At the start, each of the tools is given a definition, which introduces the respondent to the 9 questions that follow.

Polish definitions for traditional tools were based on definitions developed for the 10 traditional tools by Steiner and Gulliland (1996). The definitions for ICT-based tools were developed for this study basing on the literature (Armstrong, Landers \& Collmus, 2016; Gandomi \& Haider, 2015; McCarthy et al., 2017), then checked by researchers, their colleagues and respondents of a pilot survey for proper understanding.

\subsection{Participants}

The survey was conducted with the use of an e-questionnaire on the ankietowo.pl portal in February 2018. The portal offers a large panel of respondents rewarded in a gamified manner for market, political and social research, and declares that respondents' composition corresponds (in layers) to the demographic structure of Polish society. Data collected from such portals are nowadays used for scientific purposes (Malik, Singh, \& Chan, 2017; Kaplan, Berkley, \& Fisher, 2016) despite the limitations resulting from the specific nature of surveys, the motivation of the respondents, and the impossibility to determine the scale of participation. After all, one should expect that if respondents are interested in completing the questionnaire quickly and not in the aims of the survey or the content of the questions, then the answers reflect primarily their emotional feelings, strong and well-established beliefs, rather than the elaborate reflection. Therefore, one should expect a relatively adequate reflection of strong emotional feelings of the respondents, while detailed comparisons or in-depth differentiation analysis would be less so. Since the current study aims to verify the theses based on the emotional attitude to finding oneself in specific social situations, which are clear to each respondent and about which the general opinion of the respondent can be considered as already formed, such a way of obtaining answers provides a sufficiently adequate characterization of the respondents' attitude towards particular selection tools.

The persons from whom data were collected during the study were characterized by considerable diversity in terms of demographic characteristics, but did not form a representative sample. The sample consisted of 833 people and was dominated by female subjects $(60.5 \%)$. $30.3 \%$ of the respondents had university degrees, $17.5 \%$ were students, and the remainder had at most high-school (secondary education) degrees. The average age of the sample was 32.6 $(\mathrm{SD}=13.8)$.

\subsection{Measures}

The questionnaire considered the fact that respondents may mistake the Application questionnaire for a CV (which is a standard selection tool in Poland), therefore the questions concerning the $\mathrm{CV}$ directly preceded the ones concerning the Application questionnaire. The second assumption of the questionnaire was to avoid presenting in proximity those methods from the traditional and ICT-based groups that were to be compared. Thus, the methods were presented to the respondents in the following order: Interview, CV, Application questionnaire, Work-sample, Personal references, Long-distance interview, Assessment based on activity in games, Assessment based on game results, Internet - content-based analytics, Internet structure-based analytics.

As a consequence, in the questionnaire there were ten sets of questions regarding each given method. In every set the method was described, the more detailed the less given method (or its name) is popular in Poland. Then followed questions concerning process favorability and 
procedural justice, both measured on a seven-point scale of 1 ("strongly disagree") to 7 ("strongly agree").

Internet experience was measured by a declaration of frequency of Internet usage in non-occupational activities (many times a day, usually once a day, several times a week at most). Previous studies referring to the internet experience in e-recruitment were based on measuring it by declaring the use of the Internet in general (Sinar, Reynolds \& Paquet, 2003, p. 152), which was considered an inadequate indicator for concerns about operating via the Internet now.

Based on declared year of birth, 3 groups of generations were developed: born in 1980 or before, born between 1981 and 1994, and born in 1995 or later. Although the literature stresses that generational boundaries do not correspond to age cohorts (Woźniak, 2016), it can be assumed that the two younger age groups correspond to the blurred boundaries of generations $\mathrm{Z}$ and Y, while the oldest group - connects all older generations. Such a categorization is sufficiently consistent with the aims of the study, which treats belonging to a generation as an indicator of online experience.

Process favorability index was calculated as the mean score on the two items (,[This method] is effective for identifying people qualified for the job" and "If I did not get the job after [application of this method], I would consider that selection based on [this method] is fair"). Coefficient $\alpha$ for this index was .67 across all participants and all methods.

There were the following procedural justice variables examined: scientific evidence ([This method] is based on solid scientific research"), face validity ([This method] is a logical method for identifying qualified candidates"), opportunity to perform ("[This method] will detect individuals' important qualities that differentiate them from others" ), employer's right ("Employers have the right to obtain information by using [his method]"), respect of privacy, (reversed: “ [This method] invades candidate's personal privacy"), wide use ("[This method] is appropriate because it is widely used").

Because Principal Component Analysis across all methods revealed that respect of privacy forms a separate factor (loading 0.957), we decided to exclude this variable from the overall procedural justice score. Consequently, the procedural justice index was calculated as the mean score of procedural justice variables except respectful of privacy. That has resulted in increased reliabilities of procedural justice index (Table 2).

Table 2. Reliabilities of procedural justice index for examined selection methods

\begin{tabular}{lll}
\hline Selection method & \multicolumn{2}{l}{ Cronbach's $\alpha$ for procedural justice index } \\
\cline { 2 - 3 } & $\begin{array}{l}\text { including 'respect of } \\
\text { privacy' item }\end{array}$ & $\begin{array}{l}\text { without 'respect of privacy' } \\
\text { item }\end{array}$ \\
\hline Interviews & 0.69 & 0.78 \\
\hline C.V. & 0.71 & 0.79 \\
\hline Application questionnaire & 0.71 & 0.78 \\
\hline Work-sample & 0.70 & 0.80 \\
\hline Personal references & 0.72 & 0.82 \\
\hline Long-distance interview & 0.63 & 0.81 \\
\hline Assessment based on activity in games & 0.66 & 0.83 \\
\hline Assessment based on game results & 0.62 & 0.82 \\
\hline Internet - content-based analytics & 0.71 & 0.82 \\
\hline Internet - structure-based analytics & 0.75 & 0.85 \\
\hline Source: own compilation & &
\end{tabular}




\subsection{Statistical procedure}

All statistical analyses were completed using IBM SPSS Statistic software ( v.25). Statistical significance was set at the 0.05 level.

As Table 3 shows, both process favorability and procedural justice measures are correlated, though not very low $(<0.3)$, nor very high $(>0.9)$, then it could be informative to investigate them simultaneously as measures of selection methods' acceptance (Verma, 2015). Therefore, to examine if selection methods' type, subjects' generational affiliation, and scale of their Internet experience in non-occupational activities affect selection methods' acceptance, repeated measures multivariate analysis of variance was conducted with acceptance measures (process favorability and procedural justice) as the dependent variables. In this factorial design, there are three independent factors: Method (10 levels), Internet usage in non-occupational activities (3 levels), and Generation (3 levels). Table 3 presents means and standard deviations in each of the groups.

Table 3. Process favorability and procedural justice scores- means and standard deviations in groups

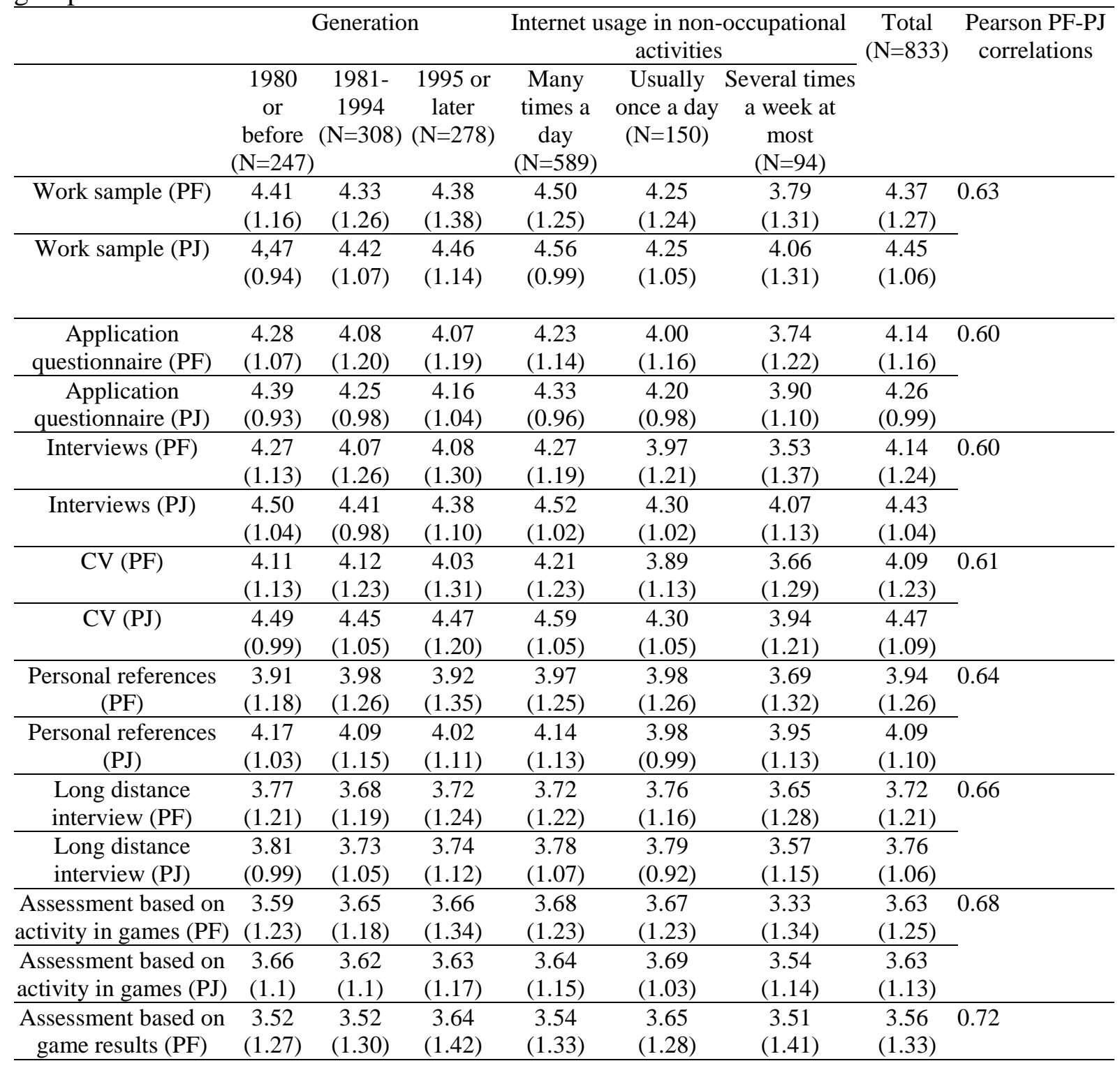




\begin{tabular}{ccccccccc}
\hline Assessment based on & 3.57 & 3.57 & 3.62 & 3.56 & 3.66 & 3.62 & 3.59 \\
game results (PJ) & $(1.11)$ & $(1.11)$ & $(1.12)$ & $(1.14)$ & $(1.02)$ & $(1.14)$ & $(1.12)$ \\
\hline Internet content- & 3.34 & 3.34 & 3.38 & 3.32 & 3.47 & 3.36 & 3.36 & 0.70 \\
based analytics (PF) & $(1.32)$ & $(1.38)$ & $(1.40)$ & $(1.40)$ & $(1.26)$ & $(1.36)$ & $(1.37)$ \\
\hline Internet content- & 3.46 & 3.41 & 3.56 & 3.45 & 3.62 & 3.43 & 3.48 \\
based analytics (PJ) & $(1.10)$ & $(1.20)$ & $(1.14)$ & $(1.20)$ & $(0.99)$ & $(1.07)$ & $(1.15)$ & 0.70 \\
\hline Internet structure- & 3.31 & 3.26 & 3.52 & 3.25 & 3.43 & 3.25 & 3.28 & 0.40 \\
based analytics (PF) & $(1.28)$ & $(1.35)$ & $(1.41)$ & $(1.38)$ & $(1.18)$ & $(1.40)$ & $(1.35)$ \\
\hline Internet structure- & 3.36 & 3.31 & 3.48 & 3.34 & 3.52 & 3.42 & 3.38 \\
based analytics (PJ) & $(1.18)$ & $(1.20)$ & $(1.26)$ & $(1.24)$ & $(1.08)$ & $(1.23)$ & $(1.21)$ \\
\hline Source: Orn
\end{tabular}

Source: own compilation. Notes: Abbreviations: PF - process favorability, PJ - procedural justice. Standard deviations are given in parentheses. All correlations are significant at the 0.01 level.

\section{Results}

The analysis of variance showed:

- $\quad$ significant multivariate effect of method: Wilks' Lambda $=0,755, F(18,807)=14,513$, $\mathrm{p}<0,001$; partial Eta Squared $=0,245$ (large),

- $\quad$ significant effect of the (method*Internet usage) interaction: Wilks' Lambda $=0,926$, $\mathrm{F}(36,1614)=1,755 ; \mathrm{p}=0.004$; partial Eta Squared $=0.038$ (small);

- no significant multivariate effects of the (method* generation * Internet usage) and the (method * generation) interactions.

Followed univariate analyses of variance (with the Greenhouse-Geisser corrections and corrected statistical significance level $\alpha=0.05 / 2=0.025$ ) revealed significant main effects of method:

- $\quad$ on process favorability scores $\mathrm{F}(6.65,5477.96)=36,43, \mathrm{p}<0.001$; Partial Eta Squared = 0.042 (small);

- on procedural justice scores $\mathrm{F}(5.00,5477.96)=86.31, \mathrm{p}<0.001$; Partial Eta Squared $=$ 0.095 (moderate);

- $\quad$ and the (method $*$ Internet_usage ) interaction effects:

- on process favorability scores $\mathrm{F}(13.30,5477.96)=4.16, \mathrm{p}<0.001$; Partial Eta Squared = 0.010 (small);

- $\quad$ on procedural justice scores $\mathrm{F}(10.01,4122.51)=5.68, \mathrm{p}<0.001$; Partial Eta Squared = 0.014 (small).

The (method * generation) interaction effects were small and insignificant at the 0.025 level.

Pairwise comparisons with Bonferroni's adjustment revealed significant differences among scores of traditional and ICT-based methods. Tables 4 and 5 present pairwise comparisons for process favorability and procedural justice mean scores. Long distance interview is the only ICT-based method not significially lower scored than each ICT-based. This partially confirms the first hypothesis (HA). 
Table 4. Pairwise comparisons of means - traditional vs ICT-based methods' process favorability scores

\begin{tabular}{|c|c|c|c|c|c|}
\hline & $\begin{array}{l}\text { Long dista } \\
\text { interview } \\
\text { (LDI) }\end{array}$ & $\begin{array}{l}\text { Activity in } \\
\text { games (AG) }\end{array}$ & $\begin{array}{l}\text { Game } \\
\text { results (GR) }\end{array}$ & $\begin{array}{l}\text { Internet - } \\
\text { content-based } \\
\text { analytics (CBA) }\end{array}$ & $\begin{array}{l}\text { Internet - } \\
\text { structure-based } \\
\text { analytics (SBA) }\end{array}$ \\
\hline \multirow{2}{*}{ Interviews (IN) } & IN $>$ LDI & IN>AG & IN $>$ GR & $\mathrm{IN}>\mathrm{CBA}$ & IN $>$ SBA \\
\hline & $\mathrm{p}=0.073$ & $\mathrm{p}<0.001$ & $\mathrm{p}<0.001$ & $\mathrm{p}<0.001$ & $\mathrm{p}<0.001$ \\
\hline \multirow[t]{2}{*}{$\mathrm{CV}$} & $\mathrm{CV}>\mathrm{LDI}$ & $\mathrm{CV}>\mathrm{AG}$ & $\mathrm{CV}>\mathrm{GR}$ & $\mathrm{CV}>\mathrm{CBA}$ & $\mathrm{CV}>\mathrm{SBA}$ \\
\hline & $\mathrm{p}=0.119$ & $\mathrm{p}<0.001$ & $\mathrm{p}<0.001$ & $\mathrm{p}<0.001$ & $\mathrm{p}<0.001$ \\
\hline \multirow{2}{*}{$\begin{array}{l}\text { Application } \\
\text { questionnaire (AQ) }\end{array}$} & AQ>LDI & $A Q>A G$ & $\mathrm{AQ}>\mathrm{GR}$ & $\mathrm{AQ}>\mathrm{CBA}$ & $\mathrm{AQ}>\mathrm{SBA}$ \\
\hline & $\mathrm{p}=0.002$ & $\mathrm{p}<0.001$ & $\mathrm{p}<0.001$ & $\mathrm{p}<0.001$ & $\mathrm{p}<0.001$ \\
\hline \multirow[t]{2}{*}{ Work sample (WS) } & $\mathrm{WS}>\mathrm{LDI}$ & $\mathrm{WS}>\mathrm{AG}$ & $\mathrm{WS}>\mathrm{GR}$ & $\mathrm{WS}>\mathrm{CBA}$ & $\mathrm{WS}>\mathrm{SBA}$ \\
\hline & $\mathrm{p}<0.001$ & $\mathrm{p}<0.001$ & $\mathrm{p}<0.001$ & $\mathrm{p}<0.001$ & $\mathrm{p}<0.001$ \\
\hline \multirow{2}{*}{$\begin{array}{l}\text { Personal references } \\
\text { (PR) }\end{array}$} & $\mathrm{PR}>\mathrm{LDI}$ & $\mathrm{PR}>\mathrm{AG}$ & PR $>$ GR & $\mathrm{PR}>\mathrm{CBA}$ & $\mathrm{PR}>\mathrm{SBA}$ \\
\hline & $\mathrm{p}=0.924$ & $\mathrm{p}<0.001$ & $\mathrm{p}<0.001$ & $\mathrm{p}<0.001$ & $\mathrm{p}<0.001$ \\
\hline
\end{tabular}

Source: own compilation

Table 5. Pairwise comparisons of means - traditional vs ICT-based methods' procedural justice scores

\begin{tabular}{|c|c|c|c|c|c|}
\hline & $\begin{array}{c}\text { Long distance } \\
\text { interview (LDI) }\end{array}$ & $\begin{array}{l}\text { Activity in games } \\
\text { (AG) }\end{array}$ & $\begin{array}{c}\text { Game results } \\
\text { (GR) }\end{array}$ & $\begin{array}{c}\text { Internet - } \\
\text { content-based } \\
\text { analytics } \\
(\mathrm{CBA})\end{array}$ & $\begin{array}{c}\text { Internet structure- } \\
\text { based analytics } \\
\text { (SBA) }\end{array}$ \\
\hline Interviews (IN) & $\begin{array}{l}\text { IN }>\text { LDI } \\
p<0.001\end{array}$ & $\begin{array}{l}\mathrm{IN}>\mathrm{AG} \\
\mathrm{p}<0.001\end{array}$ & $\begin{array}{l}\text { IN }>\text { GR } \\
p<0.001\end{array}$ & $\begin{array}{l}\mathrm{IN}>\mathrm{CBA} \\
\mathrm{p}<0.001\end{array}$ & $\begin{array}{l}\mathrm{IN}>\mathrm{SBA} \\
\mathrm{p}<0.001\end{array}$ \\
\hline $\mathrm{CV}$ & $\begin{array}{l}\text { CV }>\text { LDI } \\
p<0.001\end{array}$ & $\begin{array}{l}\mathrm{CV}>\mathrm{AG} \\
\mathrm{p}<0.001\end{array}$ & $\begin{array}{l}C V>G R \\
p<0.001\end{array}$ & $\begin{array}{l}\mathrm{CV}>\mathrm{CBA} \\
\mathrm{p}<0.001\end{array}$ & $\begin{array}{l}C V>\text { SBA } \\
p<0.001\end{array}$ \\
\hline $\begin{array}{c}\text { Application } \\
\text { questionnaire (AQ) }\end{array}$ & $\begin{array}{l}\text { AQ }>\text { LDI } \\
p<0.001\end{array}$ & $\begin{array}{l}A Q>A G \\
p<0.001\end{array}$ & $\begin{array}{l}A Q>G R \\
p<0.001\end{array}$ & $\begin{array}{c}A Q>C B A \\
p<0.001\end{array}$ & $\begin{array}{l}A Q>S B A \\
p<0.001\end{array}$ \\
\hline $\begin{array}{l}\text { Work sample } \\
\text { (WS) }\end{array}$ & $\begin{array}{l}\text { WS }>\text { LDI } \\
p<0.001\end{array}$ & $\begin{array}{l}\text { WS }>A G \\
p<0.001\end{array}$ & $\begin{array}{l}\text { WS }>\text { GR } \\
p<0.001\end{array}$ & $\begin{array}{c}\mathrm{WS}>\mathrm{CBA} \\
\mathrm{p}<0.001\end{array}$ & $\begin{array}{l}\mathrm{WS}>\mathrm{SBA} \\
\mathrm{p}<0.001\end{array}$ \\
\hline $\begin{array}{c}\text { Personal references } \\
(\mathrm{PR})\end{array}$ & $\begin{array}{l}\text { PR }>\text { LDI } \\
p<0.001\end{array}$ & $\begin{array}{l}P R>A G \\
p<0.001\end{array}$ & $\begin{array}{l}P R>G R \\
p<0.001\end{array}$ & $\begin{array}{c}\mathrm{PR}>\mathrm{CBA} \\
\mathrm{p}<0.001\end{array}$ & $\begin{array}{c}\text { PR }>\text { SBA } \\
p<0.001\end{array}$ \\
\hline
\end{tabular}

Source: own compilation

Although the (method * Internet_usage) interaction effects were small, their significance induced us to investigate group differences in the respondents' scores between different selection method and frequency of Internet usage. For this purpose, ten separate repeated measures ANOVAs were conducted for each acceptance measure (process favorability and procedural justice) as a dependent variable. The only significant outcomes concern traditional methods and - in case of process favorability- assessment based on activity in games (Table 6). 
Table 6. ANOVAs outcomes for Internet usage in non-occupational activities

\begin{tabular}{|c|c|c|c|}
\hline $\mathrm{HO}$ & Selection method & $\begin{array}{l}\text { ANOVA } \\
\text { outcome }\end{array}$ & $\begin{array}{c}\text { Pairwise comparisons with } \\
\text { Bonferroni adjustment } \\
\text { effects }\end{array}$ \\
\hline \multirow{5}{*}{$\begin{array}{l}\text { There are no differences } \\
\text { in process favorability } \\
\text { scores of [selection } \\
\text { method] among subjects } \\
\text { with different levels of } \\
\text { Internet usage in non- } \\
\text { occupational activities: } \\
\text { many times a day } \\
\text { (MTaD), usually once a } \\
\text { day (U1D), several times } \\
\text { a week at most (STaW). }\end{array}$} & Interviews & $\begin{array}{c}\mathrm{F}(2,832)= \\
16.46 \\
\mathrm{p}<0.001\end{array}$ & $\begin{aligned} \text { MTaD } & >\text { U1D }(p=0.022) \\
\text { MTaD } & \text { STaW } \quad(p<0.001) \\
\text { U1D } & >\text { STaW }(p=0.022)\end{aligned}$ \\
\hline & $\mathrm{CV}$ & $\begin{array}{c}\mathrm{F}(2,832)= \\
10.65 \\
\mathrm{p}<0.001\end{array}$ & $\begin{array}{l}\text { MTaD> U1D }(p=0.011) \\
\text { MTaD>STaW }(p<0.001)\end{array}$ \\
\hline & $\begin{array}{c}\text { Application } \\
\text { questionnaire }\end{array}$ & $\begin{array}{c}\mathrm{F}(2,832)=8.67 \\
\mathrm{p}<0.001\end{array}$ & MTaD> STaW $(\mathrm{p}<0.001)$ \\
\hline & Work sample & $\begin{array}{c}\mathrm{F}(2,832)= \\
13.73 \\
\mathrm{p}<0.001\end{array}$ & $\begin{array}{l}\text { MTaD> STaW }(p<0.001) \\
\text { U1D>STaW }(p=0.017)\end{array}$ \\
\hline & $\begin{array}{l}\text { Assessment based on } \\
\text { activity in games }\end{array}$ & $\begin{array}{c}\mathrm{F}(2,832)=3.04 \\
\mathrm{p}=0.048\end{array}$ & MTaD> STaW (p=0.047) \\
\hline \multirow{4}{*}{$\begin{array}{l}\text { There are no differences } \\
\text { in procedural justice of } \\
\text { [selection method] among } \\
\text { subjects with different } \\
\text { levels of Internet usage in } \\
\text { non-occupational } \\
\text { activities: many times a } \\
\text { day (MTaD), usually once } \\
\text { a day (U1D), several } \\
\text { times a week at most } \\
\text { (STaW). }\end{array}$} & Interviews & $\begin{array}{c}\mathrm{F}(2,832)= \\
16.46 \\
\mathrm{p}<0.001\end{array}$ & MTaD> STaW $\quad(p<0.001)$ \\
\hline & $\mathrm{CV}$ & $\begin{array}{c}\mathrm{F}(2,832)= \\
16.46 \\
\mathrm{p}<0.001\end{array}$ & $\begin{array}{l}\text { MTaD> U1D }(p=0.008) \\
\text { MTaD> STaW }(p<0.001) \\
\text { U1D> STaW }(p=0.028)\end{array}$ \\
\hline & $\begin{array}{l}\text { Application } \\
\text { questionnaire }\end{array}$ & $\begin{array}{c}\mathrm{F}(2,832)= \\
16.46 \\
\mathrm{p}<0.001\end{array}$ & MTaD> STaW $\quad(\mathrm{p}<0.001)$ \\
\hline & Work sample & $\begin{array}{c}\mathrm{F}(2,832)= \\
16.46 \\
\mathrm{p}<0.001\end{array}$ & $\begin{array}{l}\text { MTaD> U1D }(p=0.004) \\
\text { MTaD> STaW }(p<0.001)\end{array}$ \\
\hline
\end{tabular}

Source: own compilation. Note: Only outcomes with $\mathrm{p}<0.05$ are presented

Therefore, and because none of the multivariate and univariate effects associated with generation was significant, we conclude that there is no evidence of an impact of generation and internet usage on ICT-based selection methods' acceptance. Thus, hypothesis HB is wholly rejected.

\section{Discussion}

The aim of the study was to check how the chosen selection tools are assessed in terms of their fairness and whether the Internet experience is a modifier of this relationship. An additional research question aimed to check whether the anomaly identified in the 2010 Romanian study, consisting in a significantly higher acceptance of all procedurally strict selection tools than in other studies, is also true for modern Poland.

Studies have shown that the new selection tools are rated lower than the traditional corresponding tools. Unlike in the Romanian study (Ispas et al., 2010), traditional selection tools received not higher, but lower ratings than suggested by the research consensus based on meta-analyses. However, Internet-based tools are rated lower than the worst of the traditional tools tested, and - comparing their ratings to the results of meta-analyses - only slightly better than integrity or graphology tests. 
The discrepancy between the Romanian results and the results obtained here may be explained by the arguments used by Ispas et al. (2010, p. 106), stressing that Romanian respondents assessed the formalized selection processes as opposed to the arbitrary and politically based, communist policy-related and acquaintance-related processes of the real socialism period - which was longer than in other Eastern European countries. Consequently, one could indicate that Polish respondents (whose average age in 2018 was 32.6 with a standard deviation of 13.8 years, compared to 40 years in 2010 in the Romanian sample) no longer remember real socialism. Slightly lower ratings for traditional selection tools than those obtained in meta-analyses may then be explained as a certain disappointment which turned out to be the implementation of meritocracy standards in Poland, which were to be brought about by capitalism, which may be reflected in the anti-progressive results of the parliamentary elections of 2015 and 2019. However, both of these explanations are purely speculative and are based on a far-reaching interpretation of social events and contribute no additional confirmation to the data. It should be stressed, however, that the ratings of traditional tools presented in Table 3 are much closer to the data obtained in meta-analyses from studies carried out outside Eastern Europe than the results from Romanian surveys, which remain an anomaly indicating a role in assessing the fairness of a particular historical situation in which the study was carried out rather than the cultural specificity of evaluations in Eastern Europe.

This research has shown that the procedural justice of all traditional methods is rated higher than any ICT-based method. As far as process favorability is concerned, the only ICTbased method that is not rated significantly lower than all traditional methods (including its traditional counterpart) is the long-distance interview. This confirms most of the detailed hypotheses and partially confirms hypothesis A.

This result suggested that the rating of ICT-based methods depends on some latent variables, indicating fears of the Internet or knowledge of privacy risks associated with Internetbased research. Hypothesis B formulated this relationship using two intermediate indicators, namely the scale of use of the Internet and generational affiliation, as measures of knowledge about the dangers associated with the Internet. However, the verification of hypothesis B showed, that it had to be rejected because, although significant group differences in the respondents' scores between different selection methods and frequency of Internet usage were found, they were caused by differences in perception of traditional methods, not ICT-based. Such an outcome suggests that there is an alternate source of differences in the perception of the selection tools than the researched variables, which are an indicator of the "internet experience". This suggests either the inadequate operationalization of variables to capture this aspect of the Internet experience, or the need to search for a different reason, for example, in the values threatened using the Internet, rather than the Internet experience itself; in the protection of privacy or in the psychological specifics of the respondents; in the low level of trust in other people. The arguments used in the formulation of the hypotheses referred to the specific nature of new technologies and theories in the area of their perception. The results obtained suggest, however, that the sources of assessment - if the indicators of Internet experience have been correctly operationalized - should be sought in factors influencing the perception of traditional tools. Such a fact may indicate a "normalization" of technologies related to the study of online behavior in the eyes of respondents and a stronger impact - when formulating assessments of fairness - of factors relevant to selection compared to those related to experiencing new technologies. The relatively low age of the respondents and the relatively small group of people who do not use the Internet daily (less than 13\% of the sample) among the respondents would allow such an interpretation, which is consistent with the results of research on generation Z Internet behavior (Karacsony, Izsák, \& Vasa 2020) 


\section{Conclusions}

On the basis of data collected from 833 potential Polish employees' responses to an equestionnaire, it was concluded that ICT-based selection tools have a lower level of perceived fairness than their traditional counterparts. It was also found that neither the frequency of internet use nor being a member of younger generations is conducive to a higher acceptance of ICT-based methods. In addition, the anomaly identified in the Romanian study of 2010, in which a significantly higher acceptance of all procedurally strict selection tools was found than in the other studies, was not confirmed by the assessments of Polish respondents.

The results resolve some of the questions in the research gap that the paper identified (McCarthy et al., 2017) and have theoretical and practical consequences. First of all, they show that the way a particular selection procedure is carried out (in our study by using of online or traditional communication channels), is important for the level of its acceptance and that, despite the benefits for candidates of using ICT communication, candidates prefer traditional selection tools. The second theoretical consequence concerns the weak influence of age or frequency of internet use on the preferences we studied. The results suggest-although the hypothesis evidently requires further research - that the sources of differences in the assessment of traditional and ICT-based tools should be sought in different social and psychological variables that characterize candidates, rather than in their internet experience or age. Hence future research should thus focus on whether candidates' individual characteristics - such as test anxiety, individual innovativeness, core self-evaluation-influence perception of ICTbased selection methods. A second direction for continuing the research concerns the changes the experience of the Covid-19 pandemic may be causing in the perception of ICT-based selection tools. On the one hand, tools people have experience with should be perceived more favorably (Balcerak \& Woźniak 2020), as experience increases perceived ease of use. On the other hand, hasty, pandemic-driven adaptations of ICT-based methods may result in a negative perception of methods learned 'in pandemic mode'.

Bearing in mind the possible consequences of applicants' negative perception of selection methods (e.g. they may reject the job offer, not recommend the company, have a negative attitude towards the organization - cf. Woods et al., 2020), HR practice should be influenced by research on applicant reactions to no less a degree than by the predictive validity of selection methods. The generally low level of acceptance of ICT-based tools, even those that seem to be well known to respondents from everyday situations, also has practical consequences. Our study suggests that ICT-based selection tools should be used with caution, not only with older candidates who evince discomfort with new technologies (Vilčiauskaite, Savanevičienè, \& Navickas 2020), but also in the selection of representatives of younger generations. A second practical consequence is that organizations deciding to use ICT-based selection tools such as, for instance, video games need to implement activities which increase an understanding of these tools and which promote their higher fairness rating. Recent research results (Campion, Campion, \& Campion, 2019; McCarthy et al., 2017a) indicate that conducting a mock test increases the level of acceptance of the given selection tools used. The results obtained in the present study suggest that recruiters should at least consider preparing candidates in this way before they use video games (a tool constructed as an analogue to work samples). This means there is a need to conduct trial evaluations, which will allow the candidates to become acquainted not only with the game itself, but also with how the competences that it shows are assessed.

The third practical consequence is a tip for Polish recruiters to increase attention given to candidates' sense of fairness in the selection process. The results obtained in the study, which suggest that Polish candidates rate traditional selection tools lower than the research consensus 
implies, indicate that focus should be put on explaining the selection procedure in the case both of new, as of traditional tools.

The current study is of an exploratory character, so a number of limitations should be noted before wider generalizations can be made. The data used to conduct the analyses is specific. Firstly, the sample is not representative and respondents had relatively high levels of daily internet activity, which may suggest that the overall attitude towards ICT-based selection tools will be even lower. Secondly, the data in this study comes from an online survey which did not provide input on reasons for opinions given. Such opinions should be complemented by qualitative research, analyzing the reasons why ICT-based tools have been so poorly accepted.

The third group of limitations stems from the fairness research methodology itself. This methodology treats opinions expressed in the questionnaire as an adequate reflection of respondents' preferences for a selection tool. However, the selection process may be perceived differently and raise different types of concerns in respondents depending on the form of the given tool used (e.g. interview-biographic, stressful, etc.), and the way in which it is implemented (Woźniak 2019). The methodology assumes that respondents fill in the questionnaire by answering the questions in an honest and judicious way. Some of the tools, however, may evoke emotional associations (as an effect, for example, of negative individual experiences with this tool) so strong, that their responses result from emotions and not from the content of the questions. In Steiner and Gilliand's questionnaire, nine items were required to measure process favorability and procedural justice perceptions for each selection tool. When investigating several tools (as in our comparative study), the accuracy of the research may be threatened by possible fatigue and distraction of the respondents. This group of limitations is important because they may have wider theoretical consequences, due to the role of organizational justice for HR theory (Shah \& Khan 2019). There has been an increased critique of the assumptions of the methodology used in fairness research. It is suggested that as the perception of organizational justice is a key intermediary variable between organization resources and performance, this methodology needs to be revised and questionnaire research basing on imaginary situations should be replaced by measures of actual actions in small-scale natural experiments.

Meanwhile, for economic reasons, to make the selection process more effective, the crucial principle for HR departments is to constantly update knowledge not only about the technical possibilities of new selection tools, but also about the conditions that increase candidates' sense that the selection process is fair, to limit a potential negative impact on the image of the organization.

\section{Acknowledgement}

This research received no specific grant from any funding agency in the public, commercial, or not-for-profit sectors

\section{References}

Aguado, D., Rico, R., Rubico, V.J., \& Fernandez, L. (2016). Applicant reaction to social network web use in personnel Selection and Assessment. Journal of Work and Organizational Psychology, 32, 183-190.

Anderson, N. (2003). Applicant and Recruiter Reaction to New Technology in Selection: A Critical Review and Agenda for Future Research. International Journal of Selection and Assessment, 11(2-3), 121-136. 
Anderson, N., Ahmed, S., \& Costa, A. C. (2012). Applicant reactions in Saudi Arabia: Organizational attractiveness and core self-evaluation. International Journal of Selection and Assessment, 20, 197-208.

Anderson, N., Salgado, J.F., \& Hülsheger, U.R. (2010). Applicant Reactions in Selection: Comprehensive Meta-Analysis into Reaction Generalization versus Situational Specificity. International Journal of Selection and Assessment, 18(3), 291-304.

Anderson, N., \& Witvliet, C. (2008). Fairness Reactions to Personnel Selection Methods: An International Comparison between the Netherlands, the United States, France, Spain, Portugal, and Singapore. International Journal of Selection and Assessment, 16(1), 113.

Armstrong, M. B., Landers, R. N., \& Collmus, A. B. (2016). Gamifying recruitment, selection, training, and performance management: Game-thinking in human resource management. In: Emerging research and trends in gamification (pp. 140-165). IGI Global.

Balcerak, A. \& Woźniak, J. (2020). Process favorability for different types of selection methods, In: K. S. Soliman (Ed.) Education Excellence and Innovation Management: A 2025 Vision to Sustain Economic Development during Global Challenges, 14832-14842.

Bansal, G., Zahedi, F.M., \& Gefen, D. (2016). Do context and personality matter? Trust and privacy concerns in disclosing private information online. Information \& Management, $53,1-21$.

Bilgic, R., \& Acarlar, G. (2010). Fairness perceptions of selection instruments used in Turkey. International Journal of Selection and Assessment, 18, 208-214.

Blacksmith, N., Willford, J. C., \& Behrend, T. S. (2016). Technology in the employment interview: A meta-analysis and future research agenda. Personnel Assessment and Decisions, 2(1), 12-20.

Breaugh, J. A. (2008). Employee recruitment: current knowledge and important areas for future research. Human Resource Management Review, 18(3), 103-18.

Campion, M.C., Campion, E.D., \& Campion, M.A. (2019). Using practice employment tests to improve recruitment and personnel selection outcomes for organizations and job seekers. Journal of Applied Psychology, 104/9, 1089-1102.

Davis, F.D. (1989). Perceived usefulness, perceived ease of use, and user acceptance of information technology. MIS Quarterly, 13/3, 319-340.

Deal, J., Altman, D. G., \& Rogelberg, S.G. (2010). Millenials at work: What we know and what we need to do (if anything). Journal of Business and Psychology, 25/2, 191-199.

Gadomi, A., \& Haider, M. (2015). Beyond the hype: Big data concepts, methods, and analytics. International Journal of Information Management, 35/2, 137-144.

GUS (2017). Społeczeństwo informacyjne $w$ Polsce $w 2017$ r. (raport). https://stat.gov.pl/files/gfx/portalinformacyjny/pl/defaultaktualnosci/5497/2/7/1/spolecz enstwo_informacyjne_w_polsce_w_2017.pdf (1.05.2018).

Hoang, T. G., Truxillo, D. M., Erdogan, B., \& Bauer, T. N. (2012). Cross-cultural examination of applicant reactions to selection methods: United States and Vietnam. International Journal of Selection and Assessment, 20, 209-219.

Ispas, D., Ilie, A., Iliescu, D., Johnson, R.E., \& Harris, M.M. (2010). Fairness Reactions to Selection Methods: A Romanian study. International Journal of Selection and Assessment, 18/1, 102-110.

Kaplan, D., Berkley, R., \& Fisher, J. (2016). Applicant identity congruence in selection decision making: implications for Alejandro and Consuela. Human Resource Management, 55/1, 39-51.

Karacsony, P., Izsák, T., \& Vasa, L. (2020). Attitudes of Z generations to job searching through social media. Economics and Sociology, 13(4), 227-240. 
Lepak, D., \& Snell, S. (1998). Virtual HR: Strategic human resource management in the 21st century. Human Resource Management Review, 8(3), 215-234.

Liu, X., Potočnik, K., \& Anderson, N., (2016). Applicant Reactions to Selection Methods in China. International Journal of Selection and Assessment, 24/3, 298-303.

Lyons, S. T., \& Kuron, L. (2014). Generational differences in the workplace: A review of the evidence and directions for future research. Journal of Organizational Behavior, 35, 139157.

Madera, J.M. (2012). Using social networking Websites as a selection tool: The role of selection process fairness and job pursuit intention. International Journal of Hospitality Management, 31, 1276-1282.

Malik, A.R., Singh, P., \& Chan, C. (2017). High potential programs and employee outcomes: The roles of organizational trust and employee attributions. Career Development International, 22/7, 772-796.

McCarthy, J.M., Bauer, D.M., Truxillo, T.N., Anderson, N.R., Costa, A.C., \& Ahmed, S.A. (2017). Applicant Perspectives During Selection: A Review Addressing "So What?," "What's New?," and "Where to Next?". Journal of Management, 43/6, 1693 - 1725.

McCarthy, J. M., Bauer, D. M., Truxillo, T. N., Campion, M. C, Van Iddekinge, C. H., \& Campion, M. A. (2017a). Using pre-test explanations to improve test-taker reactions: Testing a set of "wise" interventions. Organizational Behavior and Human Decision Processes, 141, 43-56.

Mirowska, A. (2020). AI evaluation in selection: Effects on application and pursuit intentions. Journal of Personnel Psychology, 19(3), 142-149.

Nikolaou, I. \& Oostrom, J.K. (2015). Employee Recruitment, Selection, and Assessment. Contemporary Issues for Theory and Practice. Hove, East Sussex: Routledge.

Ployhart, R.E., Schmitt, N., \& Tippins, N.T. (2017), Solving the Supreme Problem: 100 Years of Selection and Recruitment at the Journal of Applied Psychology. Journal of Applied Psychology, 102/ 3, 291-304.

Scroggins, W.A., Thomas, S.L., \& Morris, A.A. (2008). Psychological Testing in Personnel Selection, Part II: The Refinement of Methods and Standards in Employee Selection. Public Personnel Management, 37/2, 185-198.

Shah, A. U., \& Khan, M. I. (2019). HRM-Performance Perspectives: An overview of Theoratical Challenges and Prospects. Engineering Economics, 30(3), 382-393.

Sinar, E.F., Reynolds, D.H., \& Paquet, S.I. (2003). Nothing but Net? Corporate Image and Web-based Testing. International Journal of Selection and Assessment, 11(2-3), 150157.

Snyder, J., \& Shahani-Denning, C. (2012). Fairness Reactions to Personnel Selection Methods: A Look at professional in Mumbai, India. International Journal of Selection and Assessment, 20/3, 297-307.

Steiner, D.D., \& Gilliland, S.W. (1996). Fairness Reactions to Personnel Selection Techniques in France and the United States. Journal of Applied Psychology, 81, 124-141.

Strohmeier, S., \& Kabst, R. (2009). Organisational adoption of e-HRM in Europe: An empirical exploration of major adoption factors. Journal of Managerial Psychology, 24(6), 482501.

Suen, H. Y. (2018). How passive job candidates respond to social networking site screening. Computers in Human Behavior, 85, 396-404.

Truxillo, D.M., Steiner, D.D., \& Gilliland, S.W. (2004). The Importance of Organizational Justice in Personnel Selection: Defining When Selection Fairness Really Matters. International Journal of Selection and Assessment, 12(1), 39-53. 
Truxillo, D. M., Bauer, T. N., McCarthy, J. M., Anderson, N. R., \& Ahmed, S. (2018). Applicant perspectives on employee selection systems. In D. S. Ones, N. R. Anderson, C. Viswesvaran, \& H. K. Sinangil (Eds.), The handbook of industrial, work \& organizational psychology (pp. 508-532). Thousand Oaks, CA: Sage.

Twenge, J. M. (2010). A review of the empirical evidence on generational differences in work attitudes. Journal of Business and Psychology, 25/2, 201-210.

Uggerslev, K.L., Fassina, N.E., \& Kraichy, D. (2012). Recruiting through the Stages: A Metaanalytic Test of Predictors of Applicant Attraction at Different Stages of the Recruiting Process. Personnel Psychology, 65(3), 597-660.

Venkatesh, V., Thong, J., \& Xu, X. (2012). Consumer acceptance and use of information technology: Extending the Unified Theory of Acceptance and Use of Technology. MIS Quarterly, 36(1), 157-178.

Verma, J. P. (2015). Repeated measures design for empirical researchers. John Wiley \& Sons.

Vilčiauskaitè, B., Savanevičienè, A., \& Navickas, V. (2020). Managing older talents in the context of aging society. Economics and Sociology, 13(4), 213-226.

Woods, S.A., Ahmed, S., Nikolaou, I., Costa, A.C., \& Anderson, N.R. 2020. Personnel selection in the digital age: a review of validity and applicant reactions, and future research challenges. European Journal of Work and Organizational Psychology, 29(1), 64-77. Woźniak, J. (2013). Rekrutacja - teoria i praktyka. WP PWN Warszawa.

Woźniak, J. (2014). On sponsoring and CSR involvement. Two theories explaining their effects on a company's attractiveness for candidates. Romanian Journal of Communication and Public Relations, 16/2, 57-72.

Woźniak, J. (2016). Social Media as a E-Recruitment Tool for Different Generations. Zarzadzanie Zasobami Ludzkimi, 6(113), 103-124.

Woźniak, J. (2017). Some factors hindering acceptance of three gamification solutions in motivation systems, in small and medium enterprises. Management Dynamics in the Knowledge Economy, 5/4, 663-680.

Woźniak, J. (2019). Akceptacja różnych form narzędzi selekcyjnych - przegląd literatury i wstępne wyniki badania. Zarządzanie Zasobami Ludzkimi, 5(130), 11-38.

Woźniak, J. (2020). Gamification for Sales Incentives. Contemporary Economics, 14/2, 144161. 